\title{
Depression and Anxiety Among Medical Students: A Brief Overview
}

\author{
Ahmad A Mirza (D) \\ Mukhtiar Baig (D) ${ }^{2}$ \\ Ghada M Beyari ${ }^{3}$ \\ Mohammed Aiman Halawani ${ }^{3}$ \\ Abdulrahim A Mirza ${ }^{4}$ \\ 'Department of Otolaryngology, Head \\ and Neck Surgery, Faculty of Medicine in \\ Rabigh, King Abdulaziz University, Jeddah, \\ Saudi Arabia; ${ }^{2}$ Department of Clinical \\ Biochemistry/Medical Education, Faculty \\ of Medicine in Rabigh, King Abdulaziz \\ University, Jeddah, Saudi Arabia; ${ }^{3}$ Faculty \\ of Medicine, Umm Al-Qura University, \\ Makkah, Saudi Arabia; ${ }^{4}$ Department of \\ Surgery - Division of Urology, Ministry of \\ National Guard - Health Affairs, Jeddah, \\ Saudi Arabia
}

\begin{abstract}
Depression and anxiety are highly prevalent conditions worldwide. This article reviews the extent of depression and anxiety among medical students and elucidates associated potential risk factors. In comparison to other countries, students from Middle East countries have a higher prevalence of depression. Females suffer from these conditions more commonly than males. Factors associated with these morbidities can be divided into academic and non-academic factors. There is an inconclusiveness of whether medical students experience these symptoms more commonly than their counterparts. The present review provided a cross-sectional picture of the students' psychological well-being, which is crucial to formulate a health policy for preventive and therapeutic purposes.
\end{abstract}

Keywords: anxiety, depression, mental health, students

\section{Introduction}

Globally, mental health among undergraudate students represents an important public health entity. University students face considerable demands in school and family, resulting in significant psychological stress that may lead to serious disorders and mental health issues such as depression and anxiety. As a result, university students' academic performance, physical well-being and mental health may substantially worsen over the academic career and could only be detected at an advanced stage. Additionally, studies conducted among medical school graduates showed that psychological distress was associated with suboptimal quality of patient care, patient safety and professionalism. ${ }^{1,2}$ The present review provides a cross-sectional picture of the current condition of the psychological well-being of medical students. In addition, it sheds light on significant predictors of depression and anxiety and helps to identify and manage major stressors in academic life.

\section{Methods}

For this narrative review, MEDLINE was searched for peer-reviewed publications in the English literature (publication period: from the inception untill 2018). We searched the grouping of Medical Subject Heading phrases: (medical students) AND (depression OR anxiety). Additional works was identified from these publications' reference lists. Each paper was objectively reviewed and included, as applicable, based on the presentation of primary data, the quality of the methodology used, the clarity of the findings, and the dependence on the existing instruments to quantify depression and anxiety. Abundant literature is available on this topic; we included only a few important and informative research articles in this review. The
Correspondence: Ahmad A Mirza Department of Otolaryngology, Head and Neck Surgery, Faculty of Medicine in Rabigh, King Abdulaziz University, P.O. Box 80205 , Jeddah, 21589, Saudi Arabia

Email aamirzal@kau.edu.sa 
ethical review committee's approval for this report was not required, as it was a narrative review of previously published researches.

\section{Depression}

\section{Prevalence of Depression}

Depression represents a significant health problem in university populations, with about one-third of students are affected. ${ }^{3}$ A systematic review estimated that the mean prevalence of depressive disorders in university students was $30.6 \%$, which was considerably higher than rates reported in general populations. ${ }^{3}$ Epidemiological data suggested that the prevalence of depression increased by $18.4 \%$ from 2005 to $2015 .{ }^{4}$

Regional distribution showed a high frequency of depression in the Middle East with a prevalence of $31.8 \%$, followed by North America with an incidence of 30.3\%, Asia (30.1\%), South America (26.8\%), and Europe (20\%). The estimated frequency of depression or its manifestations in medical students around the world was $27.2 \%$, according to a recent systematic review and meta-analysis. ${ }^{6}$ Another systematic review found that the prevalence of depression varied between $6.0-66.5 \%{ }^{7}$ An United Arab of Emirates (UAE) study examined depression and anxiety in medical students, doctors and members of the Medical College for Girls in Dubai. They found that $28.6 \%$ of medical undergraduates and $7.8 \%$ of medical staff had a high score for depression. ${ }^{8}$ The overall frequency of depression or its symptoms among medical undergraduates ranged from $1.4 \%$ to $73.5 \%$. ${ }^{6,9}$

\section{Difference in Gender}

Regarding gender, several studies reported significant differences between males and females, whereas others did not find any significant difference. ${ }^{10-15}$ Overall, female undergraduate students tended to have more depression than males. ${ }^{16}$ A study conducted among university students from 23 countries found that the prevalence of depressive symptoms was $19 \%$ among male students and $22 \%$ among female students. ${ }^{17}$ Similarly, when prevalence was stratified by gender, female medical students were found to have a higher prevalence of depression (31.5\%) than males $(24.2 \%) .^{5}$ Although females are more at risk, male students' high rates cause a special issue since they are less willing to seek help. ${ }^{3}$

\section{Factors Associated with Depression}

Many factors might increase students' susceptibility to depression. These factors include changes in lifestyle, financial stressors, family relationship changes, and academic worries with post-graduation life. ${ }^{3}$ Other possible risk factors that significantly increase the crude odds ratio (OR) of having major depressive disorder include female gender, younger age, lower-class years, living alone in a rented room, and financial difficulty. ${ }^{18}$ Furthermore, a study highlighted some specific factors for each academic level. Notably, 1st year students reported "volume of work" and "absence of feedback" as major stressors, while 3rd year students were stressed by "fears about future capability" and "pedagogical inadequacies". Sixth year students, on the other hand, expressed worries about "non-supportive climate" in addition to the stressors reported by the 1 st and 3 rd year students. ${ }^{12}$ Other social factors were associated with a high rate of depression such as family economic status. Higher rates of depression were reported among university students from lowincome families than those from high socioeconomic families. Moreover, those who lived in rural areas were likely to have a greater risk for depression than those living in urban areas. ${ }^{19}$ Students with substance abuse, students having a family history of depression and anxiety, and those who had lost a close relative in the past year were more likely to be depressed and anxious. ${ }^{20}$

\section{Difference Between Medical and Non- Medical Students}

Several studies evaluated the depression rate and compared medical and non-medical students. A British study compared the degree of depression in medical students with their non-medical peers and discovered that medical college students had a lower prevalence of depression generally than non-medical students. ${ }^{21}$ In contrast, a meta-analysis indicated that the depression rate among medical students was not significantly different from non-medical students. ${ }^{5}$ A Swedish study investigated the factors linked to depression and explored the frequency of depressive disorders at various academic levels among medical students. ${ }^{12}$ The study demonstrated that medical students had a higher prevalence of depressive disorders compared to the general population. 


\section{The Variation Across the Academic Years}

The incidence of depression was found to be varied across the academic years in medical school. First-year students had the highest prevalence of depression $(33.5 \%)$, and the rates gradually decreased until year 5 $(20.5 \%){ }^{5}$ According to another study, the highest rate of depression was diagnosed in medical students of the second year. ${ }^{8}$ A Pakistani study stated a high prevalence of depression among newly entered students (1st and 2nd year students) compared to senior students. ${ }^{20}$ In contrast, in another study, the risk of depression was significantly higher in third-year students $(39 \%)$ compared to first-year students $(28.4 \%)$, besides an increased level of perceived stress among the same group. $^{22}$ A study evaluated depression, anxiety, and stress disorders among medical students and revealed that the depression levels among students at the entry of medical school were similar to the general public, then progressively worsened over the academic period. ${ }^{23}$

\section{Anxiety \\ Prevalence of Anxiety}

The prevalence of anxiety among medical students has been reported from different regions and countries. According to a cross-sectional study carried out in Pakistan, a high prevalence of anxiety (47.7\%) was found among medical students. A mild, moderate, and severe anxiety symptoms were present in $27.6 \%, 13.6 \%$ and $6.5 \%$ of the students, respectively. ${ }^{24}$ In India, a study reported that $66.9 \%$ of medical undergraduates suffered from anxiety. ${ }^{16}$ A systematic review included medical colleges across Europe and countries speaking English outside North America and found that the frequency of anxiety varied between 7.7-65.5\%. ${ }^{7}$ A Turkish study showed a high frequency of anxiety (47.1\%) among medical undergraduates. ${ }^{19} \mathrm{~A}$ high prevalence rate of anxiety was also reported among medical undergraduates in an Egyptian university (73\%), and Nepal (41.1\%); while relatively lower rates were reported in Brazil (37.2\%) and Great Britain (31.2\%). ${ }^{25-28}$ In the Middle East region, a study showed $28.7 \%$ of medical students suffered from anxiety. ${ }^{8}$ A Saudi study showed that the frequency of morbid anxiety was $34.9 \%$ among medical undergraduates. ${ }^{29}$

\section{Difference in Gender}

A study carried out among medical students showed a significant gender difference with twice the rate of anxiety among females compared to males ( $40 \%$ versus $20 \%){ }^{30}$ Another study in Brazil assessed and compared the frequency and severity of symptoms of anxiety among firstand sixth-year medical students. They found that females were more likely to suffer from anxiety than males. ${ }^{31}$ In Saudi Arabia, a cross-sectional study showed a significantly higher rate of psychological morbidities, including anxiety, among premedical, 1st, 2nd and 3rd year female medical students $(89.7 \%)$ than males $(60 \%)$; however, no significant differences were found between gender in all other years. $^{32}$

\section{Factors Associated with Anxiety}

Several risk factors that predispose undergraduate medical students to psychological disorders, like anxiety, have been reported. A study in Pakistan described that drugs addicted students, students with a positive family history of depression and anxiety, and individuals who had lost a close relative in the past year were more prone to suffer from psychological disorders and being anxious than other individuals. ${ }^{20}$ Another study demonstrated that students with economic difficulties were at a higher risk for such disorders. ${ }^{33}$ In Egypt, a study estimated the frequency of depression, anxiety and stress symptoms among undergraduates in a medical college and demonstrated the relationship of such conditions with sociodemographic data. They showed that the female gender, university campus residents, pre-clinical years students, and students with lower academic accomplishment had higher scores of anxiety than other groups. ${ }^{25}$ Other issues may cause a significant effect on medical students' mental and emotional well-being and induce anxiety such as long working and study hours, mastering medical knowledge, competition, and inadequate time for non-academic activities. ${ }^{34,35}$ Additionally, anxiety was found to be positively predicted by a family history of mental disorders. ${ }^{30}$ A study highlighted students' three top concerns: academic performance, the pressure to succeed, and post-graduation plans. ${ }^{36}$ Further studies are required to determine the factors linked with mental problems such as anxiety that influence medical undergraduates' academic achievements. 


\section{Difference Between Medical and Non- Medical Students}

A study in Portugal reported that anxiety symptoms were significantly more prevalent among medical students than non-medical students. ${ }^{37}$ A systematic review that included students from the USA and Canada found greater anxiety levels among medical students than the general population.-

38 Similarly, a comparative study conducted among female students in Dammam University, Saudi Arabia revealed a decrease in well-being and higher levels of anxiety among medical compared to non-medical students as early as the start of the bachelor's program. ${ }^{39}$

\section{The Variation Across the Academic Years}

Many studies compared the levels of anxiety among different academic years in medical school; one found fluctuating rates of psychological disorders, including anxiety, among students, namely $45.86 \%$ in 1 st, $52.58 \%$ in 2 nd, $47.14 \%$ in $3 \mathrm{rd}, 28.75 \%$ in $4 \mathrm{th}$, and $45.10 \%$ in final year. ${ }^{40}$ Besides, anxiety symptoms were found to be frequent among medical students of 2 nd year $(61.6 \%){ }^{24}$ Similarly, a Brazilian study reported a higher frequency of anxiety symptoms among 1 st year medical students $(30.8 \%)$ than in 6 th year students $(9.4 \%){ }^{31}$

\section{Significance of the Findings and Recommendations}

The present narrative review showed that the prevalence of depression and anxiety is very high. The incidence of depression ranged from $1.4 \%$ to $73.5 \%$, and the anxiety ranged from $7.7 \%$ to $65.5 \%$ among medical students. Female medical students were more vulnerable to anxiety and depression than male students. The associated factors with depression and anxiety are female gender, economic condition, academic pressure, etc. Furthermore, the rate of depression and anxiety among medical students fluctuates across the academic years. This probably due to the difference in academia and student life from one school to another. Future research to estimate the global burden of these psychological morbidities in both developing and developed countries is of vital importance. Depression and anxiety cause hindrance to medical students' academic career and later to their social life. It is suggested that these factors should be considered among medical students, and students should be provided psychological counseling in their early academic years. Students' support unit should help them in alleviating their associated factors that may jeopardize their bright career.

\section{Limitation}

The present paper lacks a systematic comprehensive approach that is mandated in evidence synthesis. However, the goal was to provide a brief overview of the burden and potential risk factors of psychological impairments among medical students emphasizing the importance of synthesizing a higher level of evidence.

\section{Data Sharing Statement}

Data sharing is not applicable to this article as no datasets were generated or analyzed.

\section{Acknowledgments}

The authors gratefully acknowledge the invaluable guidance from Prof. Waleed Milaat and Prof. Iman Ramadan, professors in the Department of Community Medicine at King Abdulaziz University, Jeddah, Saudi Arabia. This article is a part of thesis submitted for the requirements of Master of Science degree in public health conferred by Department of Community Medicine, King Abdulaziz University, Jeddah, Saudi Arabia.

\section{Author Contributions}

All authors made a significant contribution to the work reported, whether that is in the conception, study design, execution, acquisition of data, analysis and interpretation, or in all these areas; took part in drafting, revising or critically reviewing the article; gave final approval of the version to be published; have agreed on the journal to which the article has been submitted; and agree to be accountable for all aspects of the work.

\section{Disclosure}

The authors declare that they have no competing interests.

\section{References}

1. Shanafelt TD, Bradley KA, Wipf JE, Back AL. Burnout and selfreported patient care in an internal medicine residency program. Ann Intern Med. 2002;136(5):358-367. doi:10.7326/0003-4819-136-5200203050-00008

2. Mareiniss DP. Decreasing GME training stress to foster residents' professionalism. Acad Med. 2004;79(9):825-831. doi:10.1097/ 00001888-200409000-00003

3. Ibrahim AK, Kelly SJ, Adams CE, Glazebrook C. A systematic review of studies of depression prevalence in university students. $J$ Psychiatr Res. 2013;47(3):391-400. doi:10.1016/j.jpsychires.2012.11.015 
4. GBD 2015 Disease and Injury Incidence and Prevalence Collaborators. Global, regional, and national incidence, prevalence, and years lived with disability for 310 diseases and injuries, 1990-2015: a systematic analysis for the Global Burden of Disease Study 2015. Lancet. 2016;388(10053):1545-1602. doi:10.1016/ S0140-6736(16)31678-6

5. Puthran R, Zhang MWB, Tam WW, Ho RC. Prevalence of depression amongst medical students: a meta-analysis. Med Educ. 2016;50 (4):456-468. doi:10.1111/medu.12962

6. Rotenstein LS, Ramos MA, Torre M, et al. Prevalence of depression, depressive symptoms, and suicidal ideation among medical students a systematic review and meta-analysis. JAMA. 2016;316(21):2214 2236. doi:10.1001/jama.2016.17324

7. Hope V, Henderson M. Medical student depression, anxiety and distress outside north america: a systematic review. Med Educ. 2014;48(10):963-979. doi:10.1111/medu.12512

8. Ahmed I, Banu H, Al-Fageer R, Al-Suwaidi R. Cognitive emotions: depression and anxiety in medical students and staff. $J$ Crit Care. 2009;24(3):e1. doi:10.1016/j.jcrc.2009.06.003

9. Prinz P, Hertrich K, Hirschfelder U, de Zwaan M. Burnout, depression and depersonalisation-psychological factors and coping strategies in dental and medical students. GMS Z Med Ausbild. 2012;29(1). doi: $10.3205 / \mathrm{zma} 000780$

10. Schwenk TL, Davis L, Wimsatt LA. Depression, stigma, and suicidal ideation in medical students. JAMA. 2010;304(11):1181-1190. doi:10.1001/jama.2010.1300

11. Peterlini M, Tibério IF, Saadeh A, Pereira JCR, Martins MA. Anxiety and depression in the first year of medical residency training. Med Educ. 2002;36(1):66-72. doi:10.1046/j.1365-2923.2002.01104.x

12. Dahlin M, Joneborg N, Runeson B. Stress and depression among medical students: a cross-sectional study. Med Educ. 2005;39 (6):594-604. doi:10.1111/j.1365-2929.2005.02176.x

13. Levine RE, Litwins SD, Frye AW. An evaluation of depressed mood in two classes of medical students. Acad Psychiatry. 2006;30(3):235237. doi:10.1176/appi.ap.30.3.235

14. Bramness JG, Fixdal TC, Vaglum P. Effect of medical school stress on the mental health of medical students in early and late clinical curriculum. Acta Psychiatr Scand. 1991;84(4):340-345. doi:10.1111/ j.1600-0447.1991.tb03157.x

15. Haldorsen H, Bak NH, Dissing A, Petersson B. Stress and symptoms of depression among medical students at the University of Copenhagen. Scand $J$ Public Health. 2014;42(1):89-95. doi: $10.1177 / 1403494813503055$

16. Venkatarao E, Iqbal S, Gupta S. Stress, anxiety \& depression among medical undergraduate students \& their socio-demographic correlates. Indian J Med Res Suppl. 2015;141(Mar2015):354-357. doi:10.4103/0971-5916.156571

17. Steptoe A, Tsuda A, Tanaka Y, Wardle J. Depressive symptoms, socio-economic background, sense of control, and cultural factors in university students from 23 countries. Int J Behav Med. 2007;14 (2):97-107. doi:10.1007/BF03004175

18. Roh MS, Jeon HJ, Kim H, Han SK, Hahm BJ. The prevalence and impact of depression among medical students: a nationwide crosssectional study in South Korea. Acad Med. 2010;85(8):1384-1390. doi:10.1097/ACM.0b013e3181df5e43

19. Bayram N, Bilgel N. The prevalence and socio-demographic correlations of depression, anxiety and stress among a group of university students. Soc Psychiatry Psychiatr Epidemiol. 2008;43(8):667-672. doi:10.1007/s00127-008-0345-x

20. Khan MS, Mahmood S, Badshah A, Ali SU, Jamal Y. Prevalence of depression, anxiety and their associated factors among medical students in Karachi, Pakistan. J Pak Med Assoc. 2006;56(12):583. doi:10.9734/BJMMR/2015/17193

21. Honney K, Buszewicz M, Coppola W, Griffin M. Comparison of levels of depression in medical and non-medical students. Clin Teach. 2010;7(3):180-184. doi:10.1111/j.1743-498X.2010.00384.x
22. Ludwig AB, Burton W, Weingarten J, Milan F, Myers DC, Kligler B. Depression and stress amongst undergraduate medical students. $B M C$ Med Educ. 2015;15(1):1-5. doi:10.1186/s12909-015-0425-z

23. Rosal MC, Ockene IS, Ockene JK, Barrett SV, Ma Y, Hebert JR. A longitudinal study of students' depression at one medical school. Acad Med. 1997;72(6):542-546. doi:10.1097/00001888-19970600000022

24. Alvi T, Assad F, Ramzan M, Khan FA. Depression, anxiety and their associated factors among medical students. J Coll Physicians Surg Pakistan. 2010;20(2):122-126.

25. Fawzy M, Hamed SA. Prevalence of psychological stress, depression and anxiety among medical students in Egypt. Psychiatry Res. 2017;255(August2016):186-194. doi:10.1016/j.psychres.2017.05.027

26. Kunwar D, Risal A, Koirala S. Study of depression, anxiety and stress among the medical students in two medical colleges of Nepal. Kathmandu Univ Med J. 2016;14(53):22-26.

27. Moutinho ILD, De Castro Pecci Maddalena N, Roland RK, et al. Depression, stress and anxiety in medical students: a cross-sectional comparison between students from different semesters. Rev Assoc Med Bras. 2017;63(1):21-28. doi:10.1590/1806-9282.63.01.21

28. Firth J. Levels and Sources of Stress in Medical Students. Br Med J. 1986;292(6529):1177-1180. doi:10.1136/bmj.292.6529.1177

29. Ibrahim NKR, Battarjee WF, Almehmadi SA. Prevalence and predictors of irritable bowel syndrome among medical students and interns in King Abdulaziz University, Jeddah. Libyan $J$ Med. 2013;8(1):21287. doi:10.3402/ljm.v8i0.21287

30. Ghodasara SL, Davidson MA, Reich MS, Savoie CV, Rodgers SM. Assessing student mental health at the Vanderbilt University School of Medicine. Acad Med. 2011;86(1):116-121. doi:10.1097/ ACM.0b013e $3181 \mathrm{ffb} 056$

31. Bassols AM, Okabayashi LS, da Silva AB, et al. First- and last-year medical students: is there a difference in the prevalence and intensity of anxiety and depressive symptoms? Rev Bras Psiquiatr. 2014;36 (3):233-240. doi:10.1590/1516-4446-2013-1183

32. Inam SB. Anxiety and Depression among Students of a Medical College in Saudi Arabia. Int J Health Sci. 2007;1(2):295-300.

33. Eisenberg D, Gollust SE, Golberstein E, Hefner JL. Prevalence and Correlates of Depression, Anxiety, and Suicidality Among University Students. Am J Orthopsychiatry. 2007;77(4):534-542. doi:10.1037/ 0002-9432.77.4.534

34. Dyrbye LN, Thomas MR, Shanafelt TD. Medical student distress: causes, consequences, and proposed solutions. Mayo Clin Proc. 2005;80(12):1613-1622. doi:10.4065/80.12.1613

35. Vitaliano PP, Russo J, Carr JE, Heerwagen JH. Medical school pressures and their relationship to anxiety. J Nerv Ment Dis. 1984;172(12):730-736. doi:10.1097/00005053-198412000-00006

36. Beiter R, Nash R, McCrady M, et al. The prevalence and correlates of depression, anxiety, and stress in a sample of college students. $J$ Affect Disord. 2015;173:90-96. doi:10.1016/j.jad.2014.10.054

37. Moreira de Sousa J, Moreira CA, Telles-Correia D. Anxiety, depression and academic performance: a study amongst Portuguese medical students versus non-medical students. Acta Med Port. 2018;31 (9):454-462. doi:10.20344/amp. 9996

38. Dyrbye LN, Thomas MR, Shanafelt TD. Systematic review of depression, anxiety, and other indicators of psychological distress among U.S. and Canadian medical students. Acad Med. 2006;81 (4):354-373. doi:10.1097/00001888-200604000-00009

39. Al-Dabal BK, Koura MR, Rasheed P, Al-Sowielem L, Makki SM, Comparative A. Study of perceived stress among female medical and non-medical university students in Dammam, Saudi Arabia. Sultan Qaboos Univ Med J. 2010;10(2):231-240.

40. Jadoon NA, Yaqoob R, Raza A, Shehzad MA, Choudhry ZS. Anxiety and depression among medical students: a cross-sectional study. $J$ Pak Med Assoc. 2010. doi:10.1111/j.1365-2929.2005.02176.x 


\section{Publish your work in this journal}

Advances in Medical Education and Practice is an international, peerreviewed, open access journal that aims to present and publish research on Medical Education covering medical, dental, nursing and allied health care professional education. The journal covers undergraduate education, postgraduate training and continuing medical education including emerging trends and innovative models linking education, research, and health care services. The manuscript management system is completely online and includes a very quick and fair peer-review system. Visit http://www.dovepress.com/testimonials.php to read real quotes from published authors.

Submit your manuscript here: http://www.dovepress.com/advances-in-medical-education-and-practice-journal 